\title{
School Counseling During the COVID-19 Crisis-From Crisis to Growth
}

\author{
Einat Heled ${ }^{1} \&$ Nitza Davidovitch ${ }^{1}$ \\ ${ }^{1}$ Department of Education, Ariel University, Israel \\ Correspondence: Nitza Davidovitch, Department of Education, Ariel University, Israel.
}

Received: August 30, 2021

Accepted: October 21, $2021 \quad$ Online Published: October 29, 2021

doi:10.5539/jel.v11n1p28

URL: https://doi.org/10.5539/jel.v11n1p28

\begin{abstract}
This study focuses on the role of school counselors during the COVID-19 crisis. Previous studies indicated that school counselling lacks a robust professional identity and an unequivocal role definition. Therefore, this study seeks to explore how the school counselors operated during the pandemic and to what extent the school counselor was a significant figure in coping with the challenges of schools, teachers, students, and parents during the crisis. The study focuses on school counselors in Israel, the structure of their work before and during the COVID crisis, and conclusions for the profession's future. Based on eleven school counselors' interviews, the research findings raised the need to hold a significant discussion and reexamination of the essence of school counseling role. They emphasize that, due to the sense of chaos and uncertainty among the school staff and students, the work of school counselors in Israel during the pandemic became limited mainly to systemic work and guidance and support of the teachers. The findings attempt to reach conclusions regarding school counselor's future work structure, clarify their role, and highlight deficiencies that afflict this role.
\end{abstract}

Keywords: school counselling, COVID-19, professional identity

\section{Introduction}

The outbreak of the COVID-19 pandemic disrupted life on almost all dimensions. It interrupted routines, patterns, and norms. Worldwide schools were compelled to close their doors, leading to innovative teaching and learning practices and institutional self-inspection (Zhao, 2020). In mid-March 2020, due to the spread of the pandemic, the Israeli educational system was closed and operated in an e-teaching format. This decision, and many subsequent ones, were reached behind closed doors - with no involvement by representatives of teachers, principals, parents, and students (Note 1). Thus, despite a great deal of experience accumulated in the system over the years concerning activity in times of emergency, the Ministry of Education coped with the crisis in a manner characterized by vagueness, confusion, and shifting contradictory instructions (Dahan et al., 2020). The chaos continued in 2021, until the pandemic died down in Israel due to the widespread vaccination campaign.

Due to the central place of schools in modern society, their closure has many consequences. The transition to e-Learning provides a particular solution on the educational dimension, but this is not a sufficient alternative for frontal lessons. Schools are places for games, activities, and social meetings that constitute an essential part of children's lives. Education institutions are a vital point of encounter between the welfare authorities and children from needy families or those subjected to violence and neglect. In the absence of a structured setting, many children receive no response to nutritional deprivation and violence. Finally, lacking educational settings for young children, many parents are unable to work, with all the financial consequences (Rivkin, 2020).

With the pandemic outbreak in Israel, distance learning was initiated with no organized instructions by the Ministry of Education: each educational institution formulated its own study program and decided independently how to execute it (Dahan et al., 2020). School counselors in Israel were among those affected by the global and local confusion and were compelled to redefine their role. The current research deals with the school counselors in Israel, the structure of their work before and during the COVID pandemic and raises conclusions regarding the future of the profession's structure.

\subsection{School Counseling in Israel}

According to the Israeli Ministry of Education definitions, school counseling is a professional service provided within the school to advance the functioning and mental well-being of the students and educational staff. The 
school counselor is responsible for promoting the students and staff's psychological, social, academic, and professional development. Therefore, when school counselors counsel and listen to the students, they do so from a point of view of the entire system, and when they meet with the rest of the educational staff, they see before them the well-being of the students as individuals within a system. In addition, school counselors must strive to lead steps to reduce the level of violence in the school and transform it into a safe and protected environment (from the website of Israel's psychological counseling service).

Employment of counselors in the schools: The role of the school counselor in Israel is complex, intricate, and not unequivocal. Therefore, the definition of the counselor's role and the extent of the position differ by school and are adapted to the school's needs. The employment terms and nature of work are affiliated with the school principal and his consumption patterns of counseling, which may change and be negotiated anew every year (Erhard, 2014).

The counselor's field of work in times of routine: A study conducted by Heled and Davidovich (2020) before the global outbreak of the coronavirus, detected confusion about the definition of the counselor's role in the Israeli educational system. As stated, the role definition according to the Israeli Ministry of Education is exceptionally intricate, vague, and unclear. Hence, this lack of clarity leads counselors to engage in various areas in the school and outside. According to the definition, counselor's work primarily follows the principles of the systemic conception. Namely, they must promote student's mental well-being within the educational organization while supporting all the other elements in the system (Deshevsky, 2009). School counselors are required to fulfil many roles in diverse fields of activity. Counselors routinely work with broad target populations within the school (principals, coordinators, teachers, homeroom teachers) as well as with relevant elements outside the school (psychologists, social workers, and other community workers) (Deshevsky, 2009). The counselors are responsible for assisting and integrating students with special needs, operating intervention plans, placement, building classes, and filling out various forms.

The counselor's work also includes individual therapy with struggling students and topic-focused groups (Erhard, 2014; Erhard \& Klingman, 2004; Tatar, 1997; Yosifon, 1998; Perlberg-Simcha \& Erhard, 2007; Cobia \& Henderson, 2003). Furthermore, school counselors in Israel are also teachers, and they must teach classes at the school to a varying extent according to the school's regulations (Deshevsky, 2009).

In Heled and Davidovich (2020) study, conducted in Israel pre-COVID period, the analysis of interviews with fifteen counselors showed that each school has a different definition of the counselor's role and extent of position, according to the school's needs. In the interviews, the counselors described an array of systemic, academic, and individual roles. Despite the primarily systemic role definition, the counselors related that the reason that had led them to study the profession was therapeutic work with students, but the systemic work and classroom teaching occupy most of their time. All the counselors interviewed in this study had given up on their dream of personal, emotional, and counseling contact with the students due to the lack of time and overloaded role definition.

A survey conducted among 948 school counselors in the United States indicates that during the pandemic, counselors did not manage to carry out direct work with students on social-emotional topics. Counselors reported that they often managed to meet logistic and administrative needs, and although these are important, it was detrimental to their ability to form connections with the students. Counselors reported that they often lack clear direction from the school management and supervisors (Savitz-Romer, Rowan-Kenyon, Nicola, Carroll, \& Hecht, 2020)

Another study performed in the US found that many counselors have argued that the boundaries had become blurred during this period, putting school counselors and the educational staff at risk of physical and emotional fatigue. The counselors found themselves navigating between personal stressors created by the pandemic and immediate needs of school and students (Strear, Duffy, \& Sunde, 2021).

\subsection{The Current Study}

Regarding the role of school counselors in Israel's educational system, due to frequent changes in the structure of studies from March 2020 to April 2021, it may be difficult to discern the counselor's role in the educational system during the crisis. At the end of a widespread vaccination campaign, current study was conducted in Israel at May 2021, when COVID pandemic was on the wane and school had resumed. When this article is being written, no study has been published describing the work of school counselors during this period, and this is a pioneer study in this respect. The purpose of this study is to examine whether and how the work of school counselors changed during the chaotic time of COVID pandemic. 


\section{Methodology}

\subsection{Research Population}

Eleven female school counselors from Israel, of different ages, school settings, residential areas, and levels of children at risk were identified and interviewed. Namely, the group of participants is heterogeneous in their demographic, professional, and personal characteristics. Out of eleven counselors, three were new counselors (1-4 years in the profession), five seniors (5-9 years in the profession), and veterans (more than 10 years in the profession). Six of the counselors work in elementary schools and five in junior high and high schools. They all work in government schools affiliated with the Israel Ministry of Education. All the eleven counselors participated in this study, were also participated in the pre-COVID study lead by Heled and Davidovich (2020).

\subsection{Research Procedure}

Prior to start the study, approval was obtained from the institutional ethical committee.

The same counselors from Heled and Davidovich (2020) were contacted and asked to voluntarily participate for another interview, and briefed about the topic, its purpose, and medium. After receiving the interviewees consent and before starting the interview, it was clarified that if the interview does not suit their opinion, they have full liberty to stop the interview at any stage. Furthermore, the interviewees were assured that their statements would be included in the study anonymously.

The interview was based on a semi-structured format. It was recorded, transcribed, and analyzed, as customary in qualitative research. The respondents were asked about their feelings, work structure, and the factors which strengthened them during the COVID pandemic.

\subsection{Analysis of the Interviews}

For data analysis, we used a research paradigm called "grounded theory", a theory constructed in the process of a study and grounded in the form of data collected throughout (Strauss \& Corbin, 1990; Gibton, 2001; Shkedi, 2003). As we review the data collected, concepts become apparent in the text. We have tagged those concepts with codes that succinctly summarize the concepts. The codes were grouped into categories. These categories became the basis of the grounded theory of the current research.

\section{Results}

Analysis of interviews revealed several vital issues that shed light on the counsellors' perceptions on their role and their experience throughout the year of 2020-2021: Changes in work structure, definition and goal of school counselor's role, school counselor's self-efficacy and satisfaction with work and feeling of self-realization during the pandemic year. We have also examined how the counselor's contact with other counselors or organizations, affected coping with the rapid changes in work routine.

\subsection{Changes in Work Structure During the COVID Pandemic}

As stated, even in routine times the role definition of counselors in Israel's educational system is unclear. The role definition, according to Israel's Ministry of Education is very intricate and vague. Hence, this lack of clarity leads counselors to engage in endless areas of responsibility (Heled \& Davidovich, 2020).

All the counselors interviewed in current study reported drastic changes in their regular and general work during the crisis. The main changes were:

1) The transition to systemic work exclusively: The term "systemic work" is a general term for endless tasks and areas of responsibility, and when no professional in the system is responsible for these, the assignment is given to the counselor. Most of the counselors in current study, reported a transition from routine systemic and individual work to only systemic work during the COVID crisis year. Before COVID crisis, Heled and Davidovich (2020) found that the counselors complained about an insufferable, suffocating workload that continually exceeds their work hours. Due to the heavy workload, they do not manage to reach students who need them; rather only what they called students on edge in urgent cases such as suicidal statements, severe violent incidents, or dropouts.

In the current study, the same counselors that were frustrated from the workload before the COVID crisis, related that the definition of their work structure was narrowed, mainly focused on guiding subject teachers and homeroom teachers occupied most of their time this year. The fact that the work was defined as more systemic and focused on several specific topics was more evident and led less to an unfocused work structure of the counselors.

A veteran counselor, whose agenda before the COVID period was individual emotional work with students, and 
guiding teachers in social-emotional work, spoke about her work this year: "I guided the teachers on Zoom regarding how to hold life skills lessons, how to conduct social and emotional groups. I was more there for them. I guided the teachers on how to hold and contain the students. I had to be more creative and think differently. I had to learn to relinquish control and let the teachers do the work that I do in regular times. Everything was different."

The counselors spoke about how hard it was for the teachers during this time and how much they needed their support, as one said: "The first assignment was to try and hold the teachers, conveying the message that the most important is communicating with the students. It was hard for the teachers because they are not familiar with how to support the students emotionally. In meetings with the homeroom teachers, the message was to maintain constant contact with students by telephone or in Zoom small groups."

The interviews raised a surprising finding. The counselors had firm views about the systemic work they were supposed to carry out. In the study by Heled and Davidovich (2020), the counselors reported unclear systemic work that includes subsections of responsibility for developing and assimilating development, intervention, prevention programs, development of the school staff, counseling and consultation for the management and teaching staff, and managing stress and crises at the school. They also reported that the fields of responsibility are interpreted differently according to the needs of school management. In contrast, it appears that during the COVID crisis, since most of the counselors focused only on systemic and not on individual work, they had more time to enhance this work. Moreover, the fields of responsibility seem to diminish slightly due to the postponement of various committees and filling forms.

\section{2) Coping with student dropout and the many students at risk:}

Due to ongoing closures of the education system, online learning and school instability, many students dropped out either from some classes or from school. According to the Director General Circular of the ministry of education in Israel: "From regular attendance to preventing dropout" (2017), the school counselors are the school's contact persons with the welfare agencies, psychological counseling service, and the attendance officer. They are partners in building the institutional intervention plan according to the needs, processes related to the transition between educational stages, and accompanying students at dropout risk and families through this process. Throughout the world, school counselors were also responsible for locating and treating students who dropped out of school (Savitz-Romer et al., 2020).

Two of the school counselors emphasize the difficulty that arose as a result of discontinued school learning or e-learning:

"The work was different because there are many more students who have dropped out. Children did not function as usual. The contact with the parents of those children who had dropped out was also different because they were also at a loss."

"I felt overburdened at work because I had to take more care of students who dropped out of lessons on Zoom. The issue of dropouts grew. Suddenly lots of students were dropping out of school. We also had another problem... some children did not have a computer at home and couldn't participate in the classes were considered dropouts. We didn't have a solution for them."

\section{3) Extreme overload at work:}

All the counselors reported extreme overload at work. In routine times, counselors are burdened with various tasks, both at school and outside. The counselors interviewed reported more significant overload than their routinely daily work for several reasons:

a. Due to frequent changes in the curricula and changes in outline determined by the Ministries of Health and Education. As one of the counselors emphasized in the interview: "It was impossible to build a work plan. Things changed very frequently. I constantly had to redo... To check the field and whose academic condition is declining, who is not in touch and how this affects him."

Another counselor highlighted the congestion created as a result of many Zoom meetings with the school staff: "I dealt with logistics when there were Zoom meetings with the homeroom teachers or staff meetings ... staff guidance on Zoom was so difficult... and it's completely different, everything was much more difficult than frontally working."

b. Overload due to isolation of teachers and students or the counselor herself, due to exposure to a COVID-19 positive patient or infection with the disease. One of the counselors suggested that the load was due to the isolation: "I gave guidance sessions to the teachers for two or three times, teamwork 
was affected, and many issues were sidelined."

c. Overload due to the state of emergency. The counselors emphasized first lockdown and beginning of the pandemic as the toughest time: "At first it was crazy. crazy. I was also working till at night. People were hysterical. In the second-round things calmed down. After the first lockdown and once clearer instructions were received from the Ministry of Education, there was still pressure, but of a different type. The staff needed us more than usual, so the work was mainly with the teachers. I hardly remember what it was like before COVID ... how I worked."

Another counselor added: "At the first lockdown, everyone was scared, and we did not know how much pressure to apply. It took time for us to understand how to treat the students emotionally."

One counselor summarized all the emergencies circumstances:

"The work was less organized, and we adhered less to the curriculum because it was dynamic. There were many emergencies: domestic violence, suicide, anxieties... lots of requests for therapy, work with the welfare, and psychiatric services. Truly working on the move..."

d. Difficulty with working from home. When schools were closed three times for almost two month each, the counselors had to work from their home. The counselors in this research apprised on those times: "During the lockdowns, I worked from home while caring for my children. Regretfully, my ability to meet the students was affected. I felt unable to see what the students were going through. The teachers too are unable to see this. I feel bad about missing lots of things."

"There were times when it was hard for me to manage time with the young children at home. It was hard to keep to a schedule... I did my best under the conditions."

\subsection{Definition and Goal of the Counselor's Role}

According to the job vision, counselors follow the principles of systemic conception, meaning that they must advance the mental well-being of students within the educational organization. The teaching staff, educational and management teams, parents, and various elements in the school's vicinity, are all partners in the process needed to achieve this goal. The development of the systemic conception in recent decades increasingly stresses the involvement of counselors in promoting educational interventions that include internal and external evaluation processes, accompanying educational teams in their work, and intentional investment in teachers and in improving the integration of students with special needs in the mainstream system (Deshevsky, 2009).

Despite many changes in routine work of school counselors during the COVID-19 crisis, majority concluded no change in the definition and goal of the counselor's role. As one of them said: "The role definition did not change at all, only the method changed. The responsibility remained the same... I was not confused. My role is obvious to me." Another counselor added: "The goal of the counselor did not change. The ultimate goal is still the mental well-being of individual at school. The only feeling is a crazy overload, and you must know how to prioritize and set limits in this setting. Sometimes I felt that I might lose control over work and its goals. The load was great because it is a new format that requires rethinking and working differently. How to help the children by looking at things from a systemic and process perspective."

Some of the counselors attested that the goal and definition of the job were actually refined during the emergency period: "We had a seminar where we talked about how COVID had clarified that the work should be with the staff and less with the students. I think that's right and that it works better. The results of this type of work are more meaningful. Giving the staff tools and providing them with reinforcement for meaningful emotional processes of teachers and students. I shall adopt the systemic work further on and focus on it."

In contrast, a new counselor who had only begun working as a school counselor several months before the beginning of the crisis revealed: "I think that the role definition has changed. Since I am a new counselor, I don't have prior experience with a normal situation. I have no basis for comparison. I only worked as a counselor for six months before COVID. I feel that for systemic work, you have to be at the school... it can't be done remotely."

The inexperience of the counselor with systemic work was manifested during the crisis, as she was unable to cope with such work alone and with no organized guidance. The lack of experience was detrimental to her work and understanding of the profession and its aim.

\subsection{Self-Efficacy/Satisfaction with One's Work}

In the interview, the counselors were asked whether they managed to perform their work well during the pandemic. The counselor's feelings were not uniform and they raised surprising results. It was precisely most of 
the senior and veteran counselors, some of whom had even been in the profession for more than 10 years, who felt lost and they had not managed to achieve their goals this year, compared to the new counselors who felt that they had performed their work well:

A counselor who had been on the job for 16 years related: "I didn't feel that I was doing my job well. I have been a counselor for many years, and I felt like an infant who is only starting to understand how the world works. It was hard for me to maintain the work limits. I was not sure that what I was doing was right. I was anxious about my functioning at the beginning. Everything got mixed up and I wasn't certain that I was functioning as I should."

Also, a counselor who had been in the school counseling system for 11 years added: "Everything was more extreme. I felt that I did my work suitably but not as perfect as I am used to... We were extremely overloaded. It was necessary to work appropriately with the homeroom teachers. There are still students who are absent, who dropped out of school. Even at present routine work involves treating problems that emerged during COVID... and it is tough to solve problems that were formed during COVID." Another counselor who had been in the profession for 10 years: "I couldn't do the work right. Because it was impossible to follow processes... We built a program or a curriculum and then there was another change ... things changed constantly."

Moreover, the senior counselors, those who have been on the job for 5-9 years, felt ambivalent about how they did their job: A counselor who had been in the system for 6 years: "I would like to do more things, for which I have no time. I'm happy with what I did, I wouldn't have done anything differently. A counselor for 6 years: "I feel that there is room for self-criticism. I would like to reach more students and to know what was happening, but I was doing what I can under these circumstances". Furthermore, a counselor working for about 9 years: "I didn't feel that I was doing the job well. The work was not face-to-face. I didn't sense the students and the teachers... It's not the same thing... It's not the same level of energy and commitment."

Surprisingly, new counselors who had been in the profession for one or two years described a completely different story: "I would like to think that I performed my work adequately. We did the most we could with the staff... There were some homeroom teachers with whom the work was harder, and others who adapted quickly. I kept good and constant contact with all the homeroom teachers and subject teachers". Another counselor for whom this was the second year on the job said: "I feel that I did my job as a counselor as well as possible. There were many positive moments with the children. A sense of meaning. I did my work excellently."

These findings contradict those of Heled and Davidovich (2020), where the veteran counselors seemed to be more comfortable in their role, with more explicit knowledge of their professional vision, more confident in themselves and the professional course they choose. In contrast, their interview before the COVID crisis, these counselors related that they are already less surprised by the system's various needs. The new counselors in that study expressed lower efficacy and a sense of confusion.

During the crisis, the opposite trend seems to have emerged. The veteran counselors, who used to working in routine times, were already familiar with their place in the system and had acquired a routine manner of functioning, sensed lost due to the change. They were also able to compare their work in the year of crisis to the others and found low efficacy. In contrast, new counselors had not yet acquired a professional identity and in-depth understanding of the role's requirements. The COVID year, with its more focused demands of the counselor, helped them to refine their identity and demands. Moreover, the fact that they were new counselors helped them because they could not compare their work during the crisis to their work in routine times, therefore satisfied with the quality and output of their work.

\subsection{Satisfaction and Self-Realization in the Profession During the COVID Period}

In current study, the counselors were asked three separate questions to examine their satisfaction with their work and sense of self-realization, during the crisis year. They were asked when and how they felt work gratification, when they felt distressed or despair, and whether they felt a sense of self-realization in the past year.

Except one counselor who saw nothing positive about the past year and felt no gratification and satisfaction at all, all the others reported a sense of gratification with at least one aspect of their work. Their answers were varied. One felt work gratification due to the new flexibility generated in work as a result of small classes, the other felt gratification due to the systemic work with teachers, management and their appreciation of her work: "I felt a lot of gratification with the conversations with staff. They came merely to share their feelings with me... and one of them said to me 'We're lucky to have you'. I felt meaningful and that what I was doing is right."

Several counselors related feeling work gratification with the contents they imparted on Zoom to the students or taught the teachers to impart as part of the "life skills" class or as enrichment: "I managed to instill a new 
language in the school, one of life skills. I managed to enlist the staff. I led an emotional program that is continuing to show success up to the present."

Other counselors related a sense of gratification with individual work with children at risk of dropout or other difficulties: "I felt lots of satisfaction when I managed to return a child to school. For three years he has been feeling unconnected to the system, and this year he managed to get a hold of himself. His success is my success." Another counselor related: "I felt gratification when I managed to get a girl who had dropped out of school this year to resume good functioning and another counselor revealed: I helped a student overcome anxiety attacks she was having due to this period. It gives me lots of satisfaction."

When the counselors were asked about moments of despair and distress in their work this year, many mentioned the time of the first lockdown, in March 2020, as the most challenging period. As one said: "I felt despair and distress in the first lockdown. COVID stressed me out, I was afraid. At work too, there was a sense of uncertainty. Another counselor related: I felt distressed and despair mainly at the beginning. There was fear and uncertainty, we didn't know what was happening... students gradually began to drop out of the Zoom. We discovered that we couldn't make children enter the Zoom. We had no tools to bring them back. That was a moment of despair and helplessness. Even today, a year later, many students not able to resume their studies."

Some counselors felt a difficulty specifically with the systemic work: "I feel despair when I see that I have no one to talk to. When the teachers and management do not follow my recommendations, and when the overload and confusion in the system prevent me from working with teachers." Another counselor spoke about the fatigue of system and of all the workers with overloaded year: "It was such a loaded year... I need a rest. There were endless meetings in the evenings... The management doesn't even understand why that is a problem. I feel that I am not appreciated." This counselor speaks about how the systemic work, day and night, led her to despair, might be due to the management does not appreciate her hard work. Some counselors spoke about moments of despair mainly due to working from home, while also having to care for their young children: "The lockdowns were hard, because I have two young children at home. I needed help all the time." Another counselor added: "The challenge in meetings is to enlist the staff... The teachers' children are also at home and it's impossible to work like that. There are constant disruptions..."

The counselors also spoke about the sense of despair when unable to treat children at risk individually as in routine times or not having proper tools to handle those children who had dropped out of school, whether hidden or actual dropouts: "I felt despair mainly when I knew that there are children who need treatment and assistance, and I was unable to help them. Even when the parents agreed to receive treatment, the welfare systems in Israel have already collapsed... There were no slots for therapy, no therapists, and private therapy is very expensive. I felt as I'm reaching a dead end. The therapeutic system at the school is deficient as there is no psychologist available at the school who can care for children specifically. I think the school can provide a therapeutic response, but this does not happen-there is no willingness and no budget, certainly not in the past year."

Again, after revealing their moments of satisfaction and despair in the last year, the counselors were asked about their sense of self-realization during this year. The answers were varied:

Five of the counselors felt that they had not realized themselves in the past year: "I have been a counselor for many years and this year I did not feel the same self-realization. I felt that I was in a survival mode. I did the best I could in these circumstances without expecting much. Maybe COVID allowed me to forgive myself for not being perfect."

Another counselor said that she thought she was not doing her job: "I didn't feel that I had realized myself, I felt that I was only putting out fires." Another complained that due to the lots of systemic office work this year, she did not realize herself and yet another felt the same because of the physical and emotional detachment from the students.

Similarly, six counselors felt that they had realized themselves despite the hardships and the overload in the past year. As one summarized: "I am certainly realizing myself this year, despite COVID and not because of it."

So, it seems that the counselor's sense of satisfaction with their work is not unequivocal and contradictory with the same counselors spoked in the study conducted by Heled and Davidovich (2020), where similar to previous studies by Erhard $(1998,2008)$ the counselors displayed medium-high satisfaction with their work and reported high mental well-being. Some of the counselors who felt that they realized themselves in their profession in routine times, felt during crisis that they did not realize themselves and this grave feelings of despair and distress. The sense of difficulty in routine times changed from dissatisfaction with the definition of the counselor's role, their compensation, and the pressures applied, to severe feelings as a result of the crisis, overload due to the 
many extreme cases, the instability of the study or home routine, and student dropout.

Heled and Davidovich (2020) found counselors reported that despite the problematic role definition, the burnout, overload, low wages and compensation, emotional and mental compensation still provides a great deal of satisfaction with counseling profession. The researchers concluded that counselors' need to help others and respond to this need through their work and feedback they receive from their surroundings about the work is satisfactory and sufficient to establish high satisfaction with the profession. Indeed, in the current study as well, although the sense of satisfaction with the profession was lower than in pro-COVID times, the counselors reported a sense of satisfaction with individual cases of success, professional appreciation, and help for the students and staff.

\subsection{Contact with Other Counselors/Organizations}

Studies have shown that consulting with colleagues and their support moderate pressure and burnout among counselors (Heled \& Davidovich, 2020; McCarthy, Kerne, Calfa, Lambert, \& Guzmán, 2010; Wilkerson \& Bellini, 2006). A study that explored stressors among school counselors found that consulting with colleagues was perceived by counselors as a factor that curbs pressure in their work (Culbreth, Scarborough, Banks-Johnson, \& Solomon, 2005). Also, Savitz-Romer and colleagues (2020) suggested that it is necessary to increase guidance and support to meet the specific needs of counselors. Since the pandemic intensified trauma, sorrow, and isolation, counselors might need explicit training in these areas.

We sought to explore whether the support of other counselors or organizations connected to school counseling contributed to the counselor's sense of confidence in her work and her satisfaction with the profession, even in the crisis times. Of the 11 counselors interviewed, only three did not utilize the support of other counselors and did not see the professional development provided by supervisors as beneficial for their work. These included two veteran counselors $(10,11$ years) and one senior counselor with 5 years in profession. One veteran counselor felt an extreme sense of crisis; she reported that she had not realized herself this year and felt lost. Support by other counselors might have been most beneficial for her. The two other counselors who had not received the support of colleagues felt medium-high efficacy and satisfaction with their profession.

The rest of the counselors, eight of them, confirmed that they had utilized the help of other counselors and various professional development courses. These included counselors who are part of a group of counselors at the school as well as counselors who work alone but received help from a supporting group. The most veteran counselor in the study, with about 16 years in the profession, summarized: "Talking to other counselors was very helpful for me. They too spoke about how hard the work was this year, the difficulty of combining work with the situation at home. It was tough for everyone to combine home and work. I was also more involved than usual in counseling activities and professional development. There were many more seminars and professional development courses that were very helpful for me. For the first time, I also signed up for professional development that was not mandatory. Seminars were professionally beneficial, they helped me maintain a balance and gave me other ideas for my work. I received a response to and validation of my work and how I do it. It was a hard year, and this involvement was the only thing that helped maintain the job boundaries. It was important for me to feel that there are others like me."

Another senior counselor, five years in the profession, who was not professionally involved with other counselors in the past, said: "I was more active with other counselors. In addition, I accompanied another counselor who was a novice. This year the psychological counseling services were significant too. I felt that they supported us, gave us a work plan... I felt that there was more professional support. Also, in the group of counselors, we shared educational content between us. During this year it was important for us to unload our feelings... and the supervisor also gave us the option in meetings with her and other counselors. I felt that I was not alone. I saw that other counselors felt like me."

In the current study some counselors are part of counselors' group at school. Like counselors who utilized the assistance from counselor's group outside the school or in professional development courses, these counselors also felt that they are not alone and that the support is meaningful for them. As found by Heled and Davidovich (2020), alos in this study we noted that counselors who work with colleagues felt more confident and less lonely.

\subsection{Insights About the Counselors' Work}

At the end of interview, the counselors were asked if they have anything to add about the year they had been through. They raised several critical points:

"The consequences of COVID will occupy us for a long time, for many years to come. COVID unbalanced the educational system, and we will have to improve the connection between the staff and students. We will not 
return to the pro-COVID challenges. I hope that this is a crisis that will lead to growth."

Another counselor related to the education system in Israel: "There should be an understanding that something in education has changed. I hope that something will change in the educational goals. Children should be taught independent learning in the 21 st century. The COVID crisis further specified children's difficulty with studying independently. I would like to change the system to studying in smaller groups with other personal measures, not only grades. The academic goals changed, and in the future I would like children's strengths to be at the center of my work rather than their deficiencies and weaknesses."

One has added about the importance of refining job definition of school counselling: "If there will be no significant change in the role definition of school counselor after this period, and it will be very grave. There must be an understanding that there are some things that counselors should not have to do. It is also impossible to do good in-depth work when one counselor is responsible for five hundred or six hundred students."

Another counselor talked about what she considered to be truly significant in her work and should change into the new role definition: "We discovered work that is more important than pedagogic work. The emotional work with the teachers and the professional staff was so meaningful. We were the adhesive, and we provided a sense of confidence and optimism. During this year I had to boost the teachers constantly."

One counselor emphasized the importance of developing the virtual learning: "Many things can be done in the virtual world. It's essential. A skill that must become familiar, Distance learning. There is a wish to instill this skill of distance learning in special education as well."

It seems that all the counselors see the COVID crisis and the attendant difficulties in their work as a possible source that will lead to growth regarding their job, a more precise definition of the profession, and further specification of counselor's responsibilities. Moreover, the counselor is part of a large, extensive, and cumbersome system. The counselors see the crisis as stimulating the system's growth towards the 21 st century, adapting it to the technological, personal, and cognitive changes happening among students and staff.

\section{Discussion}

Worldwide, the school counselors are reporting that during the COVID crisis, periods of lockdown at the schools were accompanied by chaos, sense of confusion, and a negative impact on students and their families (Strear et al., 2021). At the same time, the long-term effect of these lockdowns around the world on students and their families, the school staff in general, and school counselors in particular has not yet been clarified. In this respect, the current study is a pioneer, as it is the first to retrospectively examine the effect of school closures and chaos in the world during the global crisis on school counselors.

The research findings showed that, similar to the survey held during the pandemic in the United States, school counselors reported they did not manage to put the same effort into direct work with students on social-emotional issues, and they were often compelled to meet logistic or administrative needs. Moreover, encountered other challenges such as involvement issues and privacy on the internet (Savitz-Romer et al., 2020). Similar to the study by Strear and colleagues (2021), we found that the counselors proved difficulty of combining home and work due to the general lockdowns and hardships stemming from instability of system and frequently changing the study outlines. Similarly, in the current study, the counselors found themselves navigating between personal stressors created by the pandemic and immediate needs of the school and students. In addition, counselors in the current study reported other challenges such as hidden and actual dropout of students and need to get students back on track.

At the same time, in contrast to the survey undertaken by Savitz-Romer and colleagues (2020), school counselors in Israel were grateful for the transition to systemic work. Most of them didn't feel that the lack of direct contact with students was detrimental to their work, as they made a transition to guiding teachers on how to maintain contact with all students, particularly students at risk. Moreover, in contrast to the survey conducted in the United States, where counselors reported that they often lack clear direction by the school management and supervisors, school counselors in Israel felt enveloped by the psychological counseling service at the Ministry of Education. They felt they had been given practical and emotional tools to cope with the confusing situation, and almost all of them utilized the help of other counselors. It would be interesting to examine in future research the sources of support, the various professional development courses provided to the counselors, giving them direction to conclude how to support counselors so that they will not feel alone in the system and feel capable of doing their job.

The change in counselor's role definition to distance work, exclusively to systemic work, ended at a question whether a change had occurred in the definition of their job. In current study, the counselors interviewed agreed 
that the role definition and aim remained the same. All the counselors seek mental well-being of individuals in the school, particularly of students. The counselors reported that working towards this goal was changed, but remained constant.

It is possible that due to essential change in the manner of working towards overall aim of the role - the individual's mental well-being - the veteran counselors in the study felt a lower efficacy, a sense of confusion and helplessness than did novice counselors. The crisis year led to a reformulation of how the role is performed. Veteran counselors are accustomed to a specific work order and routine in the tasks they have been performing every day for years, and during the pandemic, the work structure changed radically. Most of the veteran counselors were less satisfied with their work, and felt less self-realization in the last year, due to the change and sense of chaos.

In contrast, new counselors, who cannot compare this year with pre-pandemic years and whose professional identity has not yet become established, might have felt the same degree of confusion and difficulty, but attributed being new in the profession and not necessarily to changes in the educational system. Moreover, during the past year, since the schools were closed for a long period, the tasks of many counselors were diminished. They were less incharge of classroom climate or individual and group work with children. Interestingly, this reduction helped them clarify their professional identity and role demands as constituting a mainly systemic role.

Almost all counselors in the study reported that they had maintained strong contact with other counselors and utilized the psychological counseling services for professional development and support. The counselors related to what degree this support was important for them and encouraged them. Most of the counselors in Israeli schools work alone or together with another counselor (some schools have more counselors). The counselor is usually alone in the system, formulates work on her own or is directed by school management to precisley focus on of her work. As stated, in crisis year, the role structure has changed, and counselors have to reformulate their role. This confusing situation could lead to helplessness, great confusion and a sense of chaos. There is no doubt that support by colleagues who are experiencing a similar situation is essential, and the support of supervisory and guidance sources is critical for best performance at this time, as confirmed by the majority of counselors in the study,

It was important for the current study researchers to ask the participating counselors whether they have insights regarding the profession and educational system compared to the past year. As claimed in another study, the COVID crisis should be treated as an opportunity to reformulate the education system in the 21 st century, and that we are now facing an unprecedented opportunity to rethink education and doubt old norms and routines so we can reimagine and rebuild education (Zhao, 2020). It would be interesting to examine what options for change and upgradation come from the counselors working within the system. The counselors suggested that the students be taught to study more independently and study in small groups. Their achievements should be measured not necessarily by grades but also by other means of strengths. All the counselors experienced the COVID crisis and the accompanying difficulties in their work as a source of growth in their role, clearer definition of the profession, and clarification of the roles with which the counselor is charged. Most of them found work focusing on teachers, their guidance on how to support the students, strengthening and containing the teachers themselves, is a significant part of the counselor's work, and they seek to make it a central aspect of their work.

In summary, the 2020-2021 COVID pandemic should be considered a crisis that leads us to renew growth in the global educational system. The advantages of this crisis should be examined as well as the weaknesses of educational system should be marked to improve the global educational system, particularly the role and responsibilities of the counselors. These research findings enhance the school counselor's role, lack of identity, and need to hold a meaningful discussion to reexamine the essence of counselor role in the school systems.

\section{References}

Cobia, D. C., \& Henderson, D. A. (2003). Handbook of school counseling. Upper Saddle River, NJ: Merrill Prentice Hall.

Culbreth, J. R., Scarborough, J. L., Banks-Johnson, A., \& Solomon, S. (2005). Role stress among practicing school counselors. Counselor Education and Supervision, 45(1), 58-71. https://doi.org/10.1002/j.1556-6978.2005.tb00130.x

Dahan, Y., Abu-Rabia-Queder, S., Yona, Y., Biton, A., Hassan, S., Levy, G., ... Pinson, H. (2020). The corona crisis and its effect on the Israeli education system. Crisis Experts Organization. Retrieved March 30, 2021, 
from

https://www.crisis-experts.org.il/wp-content/uploads/2020/04/\%D7\%9E\%D7\%A9\%D7\%91\%D7\%A8 \%D 7\%94\%D7\%A7\%D7\%95\%D7\%A8\%D7\%95\%D7\%A0\%D7\%94_\%D7\%95\%D7\%94\%D7\%A9\%D7\%A4 $\% \mathrm{D} 7 \% \mathrm{~A} 2 \% \mathrm{D} 7 \% \mathrm{AA} \% \mathrm{D} 7 \% 95 \% \mathrm{D} 7 \% \mathrm{~A} 2 \% \mathrm{D} 7 \% 9 \mathrm{C} \% \mathrm{D} 7 \% 9 \mathrm{E} \% \mathrm{D} 7 \% \mathrm{~A} 2 \% \mathrm{D} 7 \% \mathrm{~A} 8 \% \mathrm{D} 7 \% 9 \mathrm{~B} \% \mathrm{D} 7 \% \mathrm{AA}$ $\% \mathrm{D} 7 \% 94 \% \mathrm{D} 7 \% 97 \% \mathrm{D} 7 \% 99 \% \mathrm{D} 7 \% \mathrm{~A} 0 \% \mathrm{D} 7 \% 95 \% \mathrm{D} 7 \% 9 \mathrm{~A} \%{ }_{0} \mathrm{D} 7 \% 94 \% \mathrm{D} 7 \% 99 \% \mathrm{D} 7 \% \mathrm{~A} 9 \% \mathrm{D} 7 \% \mathrm{~A} \% \% \mathrm{D} 7 \%$ 90\%D7\%9C\%D7\%99\%D7\%AA_.pdf [Hebrew]

Deshevsky, A. (2009). Standards for professional practice in school counseling. Published by the Ministry of Education, Psychology and Counseling Services. [Hebrew]

Director General Circular. (2017). From regular attendance to preventing dropout. Retrieved April 18, 2021, from https://apps.education.gov.il/Mankal/Horaa.aspx?siduri=37 [Hebrew]

Erhard, R. (1998). Census of school counselors-analysis of findings. Ministry of Education, Culture, and Sports, Psychological Counseling Service. [Hebrew]

Erhard, R. (2008). Research on school counselors in Israel. Jerusalem: Ministry of Education, Culture, and Sports, Psychology and Counseling Services, Research and Development Unit. [Hebrew]

Erhard, R. (2014). School counseling-A profession in search of identity. Tel Aviv: Mofet. [Hebrew]

Erhard, R., \& Klingman, A. (Eds.) (2004). School counseling in a changing society. Tel Aviv: Ramot. [Hebrew]

Gibton, D. (2001). Grounded theory: Meaning of the data analysis and theory construction process in qualitative research. In N. S. Ben-Yehoshua (Ed.), Traditions and streams in qualitative research (pp. 195-228). Lydda: Dvir. [Hebrew]

Heled, E., \& Davidovich, N. (2020). An Occupation in Search of Identity-What Is School Counseling? Journal of Education and Learning, 9(5), 215-232. https://doi.org/10.5539/jel.v9n5p215

McCarthy, C., Kerne, V. V., Calfa, N. A., Lambert, R. G., \& Guzmán, M. (2010). An exploration of school counselors' demands and resources: Relationship to stress, biographic, and caseload characteristics. Professional School Counseling, 13(3), 146-158. https://doi.org/10.5330/PSC.n.2010-13.146

Perlberg-Simcha, L., \& Erhard, R. (2007). How counselors perceive the meaning of "systemic work". School Counselor, 14, 153-176. [Hebrew]

Rivkin, A. (2020). The risk of contagion in classrooms, the efficacy of defense means for children, and the contribution of educational institutions to spreading the virus in the community. About one month before the end of the summer vacation - what does the research say about returning to school during a pandemic? Davidson Institute, the educational arm of the Weizmann Institute of Science. Retrieved April 6, 2021 from https://davidson.weizmann.ac.il/online/sciencepanorama/\%D7\%9E\%D7\%94-\%D7\%9C\%D7\%9E\%D7\%93 \%D7\%A0\%D7\%95-\%D7\%A2\%D7\%9C-\%D7\%9C\%D7\%99\%D7\%9E\%D7\%95\%D7\%93\%D7\%99\%D7\% 9D-\%D7\%91\%D7\%A2\%D7\%99\%D7\%93\%D7\%9F-\%D7\%94\%D7\%A7\%D7\%95\%D7\%A8\%D7\%95\%D 7\%A0\%D7\%94 [Hebrew]

Savitz-Romer, M., Rowan-Kenyon, H. T., Nicola, T. P., Carroll, S., \& Hecht, L. (2020). Expanding support beyond the virtual classroom: Lessons and recommendations from school counselors during the COVID-19 crisis. Harvard Graduate School of Education \& Boston College Lynch School of Education and Human Development. Retrieved from http://hgse.me/schoolcounselors-covid19

SHEFI (Psychological counseling service). (2018). About the counseling division. Retrieved December 14, 2018, from http://cms.education.gov.il/EducationCMS/Units/Shefi/gapim/yeutz/Odot.htm [Hebrew]

Shkedi, A. (2003). Words of meaning: Qualitative research-theory and practice. Tel Aviv: Ramot. [Hebrew]

Strauss, A., \& Corbin, J. M. (1990). Basics of qualitative research: Grounded theory procedures and techniques. Sage Publications, Inc.

Strear, M., Duffy, H., \& Sunde, A. (2021). When schools go dark, school counselors shine: School counseling during a global pandemic. AIR: American Institutes for Research. Retrieved March 31, 2021, from https:/www.air.org/sites/default/files/When-Schools-Go-Dark-School-Counselors-Shine-Feb-2021.pdf

Tatar, M. (1997). Perceptions and expectations of school counselors regarding their roles. School Counseling, 6, 48-71. [Hebrew]

Wilkerson, K. (2009). An examination of burnout among school counselors guided by Stress-Strain-Coping Theory. Journal of Counseling \& Development, 87(4), 428-437. 
https://doi.org/10.1002/j.1556-6678.2009.tb00127.x

Wilkerson, K., \& Bellini, J. (2006). Intrapersonal and organizational factors associated with burnout among school counselors. Journal of Counseling \& Development, 84(4), 440-450. https://doi.org/10.1002/j.1556-6678.2006.tb00428.x

Yosifon, M. (1998). The educational system in the postmodern era: Trends of change in the role of the future educational counselor. In R. Lazovsky \& S. Vafledman (Eds.), Space and heritage in educational counseling (pp. 143-172). Even Yehuda: Reches. [Hebrew]

Zhao, Y. (2020). COVID 19 as a catalyst for educational change. Prospects, 49, 29-33. https://doi.org/10.1007/s11125-020-09477-y

\section{Notes}

Note 1. In May 2020, after the first lockdown in Israel, most of the students in all grade levels returned to school for two months, until the summer vacation. During this period, some schools and classrooms were closed due to exposure to COVID patients. In September 2020 the school year began in capsules of half-classes. At the same time, the spread of the pandemic led in two weeks to a second lockdown for about two months. In November 2020 the lower classes resumed studies, and by December also the higher classes gradually joined them on some days, but due to recurring infections a third lockdown was declared beginning from January 8, 2021. The lockdown continued for two months and in late March, when the vaccination campaign began in Israel, the educational system was gradually opened until reaching full capacity in late April. The special education system and classrooms serving at-risk students were closed only during the first lockdown in 2020; subsequently they were excluded from the instructions and studies were held as usual (Wikipedia in Hebrew, "The effect of the COVID-19 pandemic on the educational system").

\section{Copyrights}

Copyright for this article is retained by the author, with first publication rights granted to the journal.

This is an open-access article distributed under the terms and conditions of the Creative Commons Attribution license (http://creativecommons.org/licenses/by/4.0/). 